\title{
TRANSFORMATIONAL LEADERSHIP DAN TURNOVER INTENTION MELALUI JOB SATISFACTION DAN ORGANIZATIONAL COMMITMENT
}

\author{
* Aprilantinas Rizqi ${ }^{1}$, Nur Azizah Sakinah ${ }^{2}$ \\ ${ }^{1}$ Program Manajemen Bandar Udara, Stp Aviasi, Jakarta, Indonesia
}

*Email Korespondensi: arizky@stp-aviasi.ac.id

\section{ARTIKEL INFORMASI}

Diterima:

3 March 2021

Direvisi:

15 April 2021

Dipublikasi:

16 Mei 2021

\begin{abstract}
ABSTRAK
Penelitian ini bertujuan untuk mengetahui pengaruh transformational leadership terhadap turnover intention karyawan melalui peran mediasi job satisfaction dan organizational commitment pada PT. ANJ Tbk di Medan. Penelitian ini melibatkan 200 karyawan PT. ANJ Tbk di Medan. Penelitian ini menggunakan pendekatan kuantitatif. Teknik analisis data yang digunakan dalam penelitian ini menggunakan software AMOS 20 dan analisis mediasi dilakukan dengan Sobel Test. Hasil penelitian menunjukkan bahwa transformational leadership berpengaruh positif dan signifikan terhadap job satisfaction dan organizational commitment dan berpengaruh negatif terhadap turnover intention. Job satisfaction berpengaruh positif dan signifikan terhadap organizational commitment dan berpengaruh positif dan tidak signifikan terhadap turnover intention dan tidak memediasi pengaruh transformational leadership terhadap turnover intention, sedangkan organizational commitment berpengaruh negatif dan tidak signifikan terhadap turnover intention dan tidak memediasi pengaruh kepemimpinan transformasional terhadap turnover intention.
\end{abstract}

Kata Kunci: Transformational Leadership, Job Satisfaction, Organizational Commitment, Turnover Intention

\section{PENDAHULUAN}

Praktek kinerja suatu perusahaan dipengaruhi oleh sikap dan perilaku karyawan di dalamnya. Salah satu bentuk sikap karyawan yang menentukan kinerja suatu perusahaan adalah turnover intention. Turnover intention didefinisikan sebagai keinginan seseorang untuk keluar dari perusahaan. Keinginan pindah karyawan mengacu pada keinginan karyawan mengenai kelanjutan hubungannya dengan perusahaan dan belum diwujudkan dalam tindakan pasti meninggalkan organisasi (hanya berupa perasaan atau keinginan), sedangkan turnover lebih mengarah pada kenyataan akhir karyawan (tindakan pasti atau perilaku) yang dihadapi organisasi atau perusahaan berupa keluarnya sehingga menyebabkan pengurangan jumlah karyawan pada periode tertentu, misalnya karyawan yang mengundurkan diri atas permintaan sendiri, pensiun, pemberhentian langsung dari perusahaan atau pemberhentian sementara (Panggabean, 2004).

Turnover pada karyawan dapat menimbukan biaya yang sangat tinggi seperti rekruitmen, pelatihan, wawancara, seleksi dan biaya kompensasi atau tunjangan (Kumar, Charles dan Peter, 2011) sedangkan turnover intention akan menimbulkan dampak negatif bagi perusahaan yang dapat menciptakan 
ketidakstabilan dan ketidakpastian (ucertainity) terhadap kondisi tenaga kerja serta dalam peningkatan sumber daya manusia. Oleh karena itu perusahaan menjadi tidak efektif dan dapat kehilangan karyawan yang sudah memiliki pengalaman sebelumnya (Lekatompessy, 2003).

Penelitian ini dilakukan terhadap para karyawan yang bekerja di PT. ANJ di Medan dengan memperhatikan faktor-faktor yang mempengaruhi seperti transformational leadership style, job satisfaction, dan organizational commitment. Populasi perusahan ini adalah 360 karyawan baik dari tingkat pendidikan SD sampai S2 dengan tujuan untuk meningkatkan kualitas SDM dan mencegah turnover intention di masa yang akan datang.

\section{KAJIAN PUSTAKA}

\section{Transformational Leadership Style}

Ngadiman dan Ratmawati (2013) transformational leadership style dapat didefinisikan sebagai kepemimpinan yang meliputi usaha untuk perubahan organisasi. Menurut Robbins dan Timothy (2015) bahwa transformational leadership style terdiri dari empat aspek yang meliputi; (a) idealized influence yang mempunyai makna bahwa seorang pemimpin transformasional harus berkharisma yang mampu mempengaruhi bawahan untuk mengikuti pimpinan; (b) inspirational motivation yang mempunyai makna bahwa karakter seorang pemimpin yang mampu menerapkan standar yang tinggi akan tetapi sekaligus mampu mendorong bawahan untuk mencapai standar tersebut; (c) intellectual stimulation adalah karakter seorang pemimpin yang mampu mendorong bawahannya untuk menyelesaikan permasalahan dengan cermat dan rasional; (d) individualized consideration berarti karakter seorang pemimpin yang mampu memahami perbedaan individual para bawahannya.

\section{Job Satisfaction}

Menurut Robbins dan Timothy (2015) job satisfaction dapat diartikan sebagai sikap umum terhadap pekerjaan seseorang, yang menunjukkan perbedaan antara jumlah penghargaan yang diterima pekerja dan jumlah yang mereka yakini seharusnya mereka terima. Mathis dan Jackson (2016) menyatakan bahwa job satisfaction adalah keadaan emosi yang positif dari mengevaluasi pengalaman kerja seseorang. Job satisfaction berhubungan dengan variabel-variabel seperti turnover, tingkat absensi, umur, tingkat pekerjaan, dan ukuran organisasi perusahaan, (Mangkunegara, 2009).

\section{Organizational Commitment}

Menurut Nagar (2012), organizational commitment adalah tingkat dimana karyawan yakin dan menerima tujuan organisasi, serta berkeinginan untuk tetap tinggal dengan organisasi tersebut. Organizational commitment dibangun atas dasar kepercayaan individu atas nilai-nilai organisasional, kerelaan individu dalam membantu mewujudkan tujuan organisasional dan kesetiaan untuk tetap menjadi anggota organisasi. Oleh karena itu Organizational commitment akan menimbulkan rasa ikut memiliki baik individu terhadap organisasi. Organizational commitment menunjukkan tingkat keyakinan dan loyalitas individu terhadap organisasinya atau intensitas seseorang untuk mengidentifikasi dirinya serta tingkat keterlibatannya dalam organisasi (Indriyani dan Wisnu, 2011)

\section{Turnover Intention}

Turnover intention dapat didefinisikan sebagai keinginan karyawan untuk keluar dari pekerjaannya yang belum diwujudkan dalam tindakan pasti meninggalkan organisasi, (Bramantara, 2015).

Tabel 1. Pengembangan Hipotesis

\begin{tabular}{|c|c|c|}
\hline Hipotesis & Deskripsi & Peneliti \\
\hline $\mathrm{H}_{1}$ & $\begin{array}{l}\text { Transformational Leadership style memiliki pengaruh } \\
\text { yang positif dan signifikan terhadap Job Satisfaction }\end{array}$ & $\begin{array}{l}\text { Zahari dan Shurbagi } \\
\text { (2012) }\end{array}$ \\
\hline $\mathrm{H}_{2}$ & $\begin{array}{l}\text { Transformational Leadership style memiliki pengaruh } \\
\text { yang positif dan signifikan terhadap organizational } \\
\text { commitment }\end{array}$ & Ismail et al (2011) \\
\hline $\mathrm{H}_{3}$ & $\begin{array}{l}\text { Transformation Leadership Style memiliki pengaruh } \\
\text { negatif dan signifikan terhadap Turnover Intention }\end{array}$ & Gul et al (2012) \\
\hline
\end{tabular}




\begin{tabular}{|c|c|}
\hline $\mathrm{H}_{4}$ & $\begin{array}{l}\text { Job satisfaction memiliki pengaruh yang positif dan } \\
\text { signifikan terhadap organizational commitment }\end{array}$ \\
\hline $\mathrm{H}_{5}$ & $\begin{array}{l}\text { Job satisfaction memiliki pengaruh negatif dan } \\
\text { signifikan terhadap turnover intention }\end{array}$ \\
\hline $\mathrm{H}_{6}$ & $\begin{array}{l}\text { Organizational Commitment memiliki pengaruh yang } \\
\text { negatif dan signifikan terhadap turnover intention }\end{array}$ \\
\hline $\mathrm{H}_{7}$ & $\begin{array}{l}\text { Job satisfaction memediasi pengaruh transformational } \\
\text { leadership stye terhadap turnover intention }\end{array}$ \\
\hline $\mathrm{H}_{8}$ & $\begin{array}{l}\text { Organizational commitment dapat memediasi pengaruh } \\
\text { antara transformational leadership style terhadap } \\
\text { turnover intention }\end{array}$ \\
\hline
\end{tabular}

Hasan (2012)

Sartika (2014)

Indraprasti (2011)

Lim, Loo dan Lee (2017)

Gul et al. (2012)

\section{METODE}

\section{Populasi dan Sample}

Metode penarikan sampel yang di gunakan pada peneltian ini adalah purposive sampling yaitu penarikan sampel berdasarkan pertimbangan dimana sampel yang dipilih didasarkan pada kriteria-kriteria tertentu. Sampel yang dipilih yaitu karyawan yang bekerja di PT. Austindo Nusantara Jaya Agri Tbk di Medan. Populasi penelitian pada bulan November 2017 sebanyak 360 karyawan. Penentuan ukuran sampel ini dilakukan dengan menggunakan rumus Slovin menurut Tejada and Raymond (2012) adalah sebagai berikut :

$$
\mathrm{n}=\frac{360}{1+360(0,05)^{2}}=189 \text { karyawan } / \text { responden }
$$

Penyebaran kuesioner sejumlah 200 di PT. Austindo Nusantara Jaya Agri. Setelah diperiksa kembali ada bebarapa kuesioner tidak di isi sesuai dengan petunjuk yang sudah diberikan sejumlah 8 . Kuesioner yang bisa diterima untuk dilakukan penelitian adalah sejumlah 192. Dengan demikian sampel tersebut sudah mewakili 189 responden yang diinginkan.

\section{Variabel dan Pengukuran}

Variabel - variabel yang digunakan dalam penelitian ini adalah transformational leadership style sebagai variabel independen, turnover intention sebagai variabel dependen, dan job satisfaction dan organizational commitment sebagai variabel mediasi.

Untuk keperluan analisis kuantitatif pada penelitian ini, maka jawaban responden dapat diberi skor lima Skala Likert ( $1=$ sangat tidak setuju, $2=$ tidak setuju, $3=$ kurang setuju, $4=$ setuju, dan $5=$ sangat setuju).

\section{HASIL DAN PEMBAHASAN}

\section{Uji Validitas}

Hasil pengujian untuk variabel transformational leadership style yang terdiri dari 4 dimensi menunjukkan untuk 3 dimensi yaitu inspirational motivation, intellectual motivation dan intellectual stimulation bahwa seluruh indikator yang digunakan masing-masing dimensi bersifat valid seperti ditunjukkan dengan nilai factor loading $>0,4$ sedangkan dimensi idealized influence hanya 1 indikator yang tidak valid dengan nilai factor loading $<0,4$. Dengan demikian untuk variabel transformational leadership yang terdiri dari 4 dimensi, hanya ada 1 indikator yang harus dihilangkan karena tidak valid.

Pengujian validitas untuk variabel turnover intention yang terdiri dari 4 indikator menunjukkan bahwa ada 2 indikator yang valid dengan nilai factor loading $>0,4$, sedangkan ada 2 indikator yang lain tidak valid $<0,4$ dinyatakan tidak valid. Dengan demikian untuk variable turnover intention ada 2 indikator yang harus dihilangkan karena tidak valid. Hasil pengujian untuk variabel job satisfaction dan organizational commitment menunjukkan bahwa semua indikatornya adalah terbukti valid dengan nilai factor loading $>0,4$.

\section{Tabel 2. Hasil Uji Validitas}

\begin{tabular}{cccc}
\hline Variabel & Indikator & Factor Loading & Keterangan \\
\hline Idealized Influence & II1 & 0,372 & Tidak valid \\
\hline & II2 & 0,730 & Valid \\
\hline
\end{tabular}




\begin{tabular}{|c|c|c|c|}
\hline & II 3 & 0,444 & Valid \\
\hline & III & 0,824 & Valid \\
\hline & II5 & 0,831 & Valid \\
\hline \multirow[t]{4}{*}{ Inspirational Motivation } & IM1 & 0,821 & Valid \\
\hline & IM2 & 0,754 & Valid \\
\hline & IM3 & 0,847 & Valid \\
\hline & IM4 & 0,895 & Valid \\
\hline \multirow[t]{4}{*}{ Intellectual Stimulation } & IS1 & 0,813 & Valid \\
\hline & IS2 & 0,683 & Valid \\
\hline & IS3 & 0,815 & Valid \\
\hline & IS4 & 0,800 & Valid \\
\hline \multirow[t]{2}{*}{ Individualized Consideration } & $\mathrm{IC} 1$ & 0,901 & Valid \\
\hline & IC2 & 0,901 & Valid \\
\hline \multirow[t]{4}{*}{ Turnover Intention } & TI1 & $-0,639$ & Tidak valid \\
\hline & TI2 & 0,903 & Valid \\
\hline & TI3 & 0,903 & Valid \\
\hline & TI4 & $-0,374$ & Tidak valid \\
\hline \multirow[t]{10}{*}{ Job Satisfaction } & JS1 & 0,721 & Valid \\
\hline & JS2 & 0,719 & valid \\
\hline & JS3 & 0,676 & Valid \\
\hline & JS4 & 0,702 & Valid \\
\hline & JS5 & 0,697 & Valid \\
\hline & JS6 & 0,772 & Valid \\
\hline & JS7 & 0,749 & Valid \\
\hline & JS8 & 0,749 & Valid \\
\hline & JS9 & 0,714 & Valid \\
\hline & JS10 & 0,724 & Valid \\
\hline \multirow[t]{6}{*}{ Organizational Commitment } & OC1 & 0,728 & Valid \\
\hline & OC2 & 0,758 & Valid \\
\hline & OC3 & 0,682 & Valid \\
\hline & OC4 & 0,809 & Valid \\
\hline & OC5 & 0,619 & Valid \\
\hline & OC6 & 0,725 & Valid \\
\hline
\end{tabular}

Sumber: data diolah

\section{Uji Reliabilitas}

Menurut Sekaran (2013), dasar pengambilan keputusan uji reliabilitas ini adalah sebagai berikut:

a. Jika koefisien Cronbach's Alpha $\geq 0,6 \longrightarrow$ maka Cronbach's Alpha acceptable (construct reliable).

b. Jika koefisien Cronbach's Alpha $<0,6 \longrightarrow$ maka Cronbach's Alpha poor acceptable (construct unreliable).

Tabel 3. Hasil Uji Reliabilitas

\begin{tabular}{ccl}
\hline Variabel & $\begin{array}{c}\text { Cronbach's } \\
\text { Alpha }\end{array}$ & Keterangan \\
\hline Idealized Influence & 0,671 & Reliabel \\
\hline Inspirational Motivation & 0,846 & Reliabel \\
\hline Intellectual Stimulation & 0,779 & Reliabel \\
\hline Individualized Consideration & 0,767 & Reliabel \\
\hline Turnover Intention & 0,774 & Reliabel \\
\hline Job Satisfaction & 0,897 & Reliabel \\
\hline Organizational Commitment & 0,810 & Reliabel \\
\hline
\end{tabular}

Sumber: data diolah

Hasil pengujian reliabilitas dapat dilihat pada tabel 3 bahwa semua variabel adalah $\geq 0.6$ (reliabel). 


\section{Pengujian Hipotesis}

Analisa data diperoleh dari hasil pengujian terhadap hipotesis. Tujuan dari pengujian hipotesis adalah untuk menolak hipotesis null $\left(\mathrm{H}_{0}\right)$ sehingga hipotesis alternatif $\left(\mathrm{H}_{\mathrm{a}}\right)$ bisa diterima. Hal ini dapat dilakukan dengan melihat nilai signifikan dari tiap-tiap hubungan. Penjelasan dalam analisis hasil berkaitan dengan pengujian hipotesis yang diajukan dalam penelitian dengan menggunakan model SEM untuk menjawab masalah dalam penelitian ini. Ada 2 tahapan di dalam penggunaan model SEM yaitu:

\section{Pengujian goodness of fit model}

Hasil pengujian goodness of fit pada tabel 5 secara keseluruhan menghasilkan koefisien model fit yang baik. Kriteria RMSEA, IFI dan CFI menghasilkan kesimpulan model fit sementara untuk kriteria marginal fit dihasilkan untuk kriteria GFI, RFI dan TLI. Untuk chi-square menghasilkan kesimpulan model dengan tidak fit. Dengan demikian kriteria model fit terdapat tiga yang fit, tiga marginal fit dan satu tidak fit maka pengujian hipotesis teori dapat dilanjutkan.

Tabel 4. Hasil Pengujian Goodness of Fit

\begin{tabular}{cccc}
\hline Goodness of fit index & $\begin{array}{c}\text { Criteria } \\
\text { (cut-off value) }\end{array}$ & Hasil & Kesimpulan \\
\hline $\mathrm{X}^{2}$ - Chi-square & Diharapkan kecil & 732,502 & \\
Significance probability & $\geq 0,05$ & 0,000 & Model tidak fit \\
RMSEA & $\leq 0,1$ & 0,065 & Model fit \\
GFI & $\geq 0,90$ & 0,784 & Marginal fit \\
IFI & $\geq 0,90$ & 0,903 & Model fit \\
RFI & $\geq 0,90$ & 0,760 & Marginal fit \\
TLI & $\geq 0,90$ & 0,890 & Marginal fit \\
CFI & $\geq 0,90$ & 0,901 & Model fit \\
\hline
\end{tabular}

Sumber : data diolah

\section{Pengujian Hipotesis Teori}

Hasil pengolahan untuk model SEM dapat dilihat pada tabel 6 dan hasil test hipotesis teori penelitian dapat dilihat pada table 5. Penjelasan mengenai pengujian hipotesis yang diajukan dalam penelitian ini dapat dilhat sebagai berikut:

Tabel 5. Hasil Estimasi Direct Effect Model SEM

\begin{tabular}{|c|c|c|c|c|c|}
\hline Hipotesis & Deskripsi & Estimate & C.R. & 1-Tailed P & Kesimpulan \\
\hline $\mathrm{H}_{1}$ & $\begin{array}{l}\text { Transformational } \\
\text { Leadership style } \\
\text { memiliki pengaruh yang } \\
\text { positif dan signifikan } \\
\text { terhadap Job } \\
\text { Satisfaction }\end{array}$ & 0.233 & 5.113 & 0.000 & $\begin{array}{l}\text { Ho gagal } \\
\text { diterima }\end{array}$ \\
\hline $\mathrm{H}_{2}$ & $\begin{array}{l}\text { Transformational } \\
\text { Leadership style } \\
\text { memiliki pengaruh yang } \\
\text { positif dan signifikan } \\
\text { terhadap organizational } \\
\text { commitment }\end{array}$ & 0.164 & 3.448 & 0.000 & $\begin{array}{l}\text { Ho gagal } \\
\text { diterima }\end{array}$ \\
\hline $\mathrm{H}_{3}$ & $\begin{array}{l}\text { Transformational } \\
\text { Leadership Style } \\
\text { memiliki pengaruh } \\
\text { negatif dan signifikan } \\
\text { terhadap Turnover } \\
\text { Intention }\end{array}$ & -0.280 & -3.351 & 0.000 & $\begin{array}{l}\text { Ho gagal } \\
\text { diterima }\end{array}$ \\
\hline
\end{tabular}




\begin{tabular}{clcccc}
\hline $\mathrm{H}_{4} \quad \begin{array}{l}\text { Job satisfaction } \\
\text { memiliki pengaruh yang } \\
\text { positif dan signifikan } \\
\text { terhadap Organizational } \\
\text { commitment }\end{array}$ & 0.812 & 6.007 & 0.000 & $\begin{array}{l}\text { Ho gagal } \\
\text { diterima }\end{array}$ \\
\hline & $\begin{array}{l}\text { Job Satisfaction } \\
\text { memiliki pengaruh yang } \\
\text { positif dan tidak } \\
\text { signifikan terhadap } \\
\text { Turnover Intention }\end{array}$ & 0.116 & 0.560 & 0.287 & Ho diterima \\
& $\begin{array}{l}\text { Organizational } \\
\text { Commitment } \text { memiliki } \\
\text { pengaruh yang negatif } \\
\text { dan tidak signifikan } \\
\text { terhadap turnover } \\
\text { intention }\end{array}$ & -0.022 & -0.123 & 0.451 & Ho diterima \\
$\mathrm{H}_{6}$ & & & & \\
\hline
\end{tabular}

Sumber : data diolah

Tabel 6. Hasil Test Hipotesis Teori Direct Effect

\begin{tabular}{|c|c|c|c|c|}
\hline Hipotesis & Deskripsi & Peneliti & Hasil Test & Kesimpulan \\
\hline $\mathrm{H}_{1}$ & $\begin{array}{l}\text { Transformational } \\
\text { Leadership style } \\
\text { memiliki pengaruh } \\
\text { yang positif dan } \\
\text { signifikan terhadap } \\
\text { Job Satisfaction }\end{array}$ & $\begin{array}{c}\text { Zahari dan } \\
\text { Shurbagi } \\
\text { (2012) }\end{array}$ & $\begin{array}{l}\text { Transformational } \\
\text { Leadership style } \\
\text { memiliki pengaruh } \\
\text { yang positif dan } \\
\text { signifikan terhadap } \\
\text { Job Satisfaction }\end{array}$ & Mendukung \\
\hline $\mathrm{H}_{2}$ & $\begin{array}{l}\text { Transformational } \\
\text { Leadership style } \\
\text { memiliki pengaruh } \\
\text { yang positif dan } \\
\text { signifikan terhadap } \\
\text { organizational } \\
\text { commitment }\end{array}$ & $\begin{array}{l}\text { Ismail et al } \\
\quad(2011)\end{array}$ & $\begin{array}{l}\text { Transformational } \\
\text { Leadership style } \\
\text { memiliki pengaruh } \\
\text { yang positif dan } \\
\text { signifikan terhadap } \\
\text { organizational } \\
\text { commitment }\end{array}$ & Mendukung \\
\hline $\mathrm{H}_{3}$ & \begin{tabular}{lr}
\multicolumn{2}{l}{ Transformation } \\
Leadership & Style \\
memiliki & pengaruh \\
negatif dan & signifikan \\
terhadap & Turnover \\
Intention & \\
\end{tabular} & $\begin{array}{c}\text { Gul et al } \\
\text { (2012) }\end{array}$ & $\begin{array}{l}\text { Transformation } \\
\text { Leadership Style } \\
\text { memiliki pengaruh } \\
\text { negatif dan signifikan } \\
\text { terhadap Turnover } \\
\text { Intention }\end{array}$ & Mendukung \\
\hline $\mathrm{H}_{4}$ & $\begin{array}{l}\text { Job satisfaction } \\
\text { memiliki pengaruh } \\
\text { yang positif dan } \\
\text { signifikan terhadap } \\
\text { organizational } \\
\text { commitment }\end{array}$ & $\begin{array}{l}\text { Hasan } \\
(2012)\end{array}$ & $\begin{array}{l}\text { Job satisfaction } \\
\text { memiliki pengaruh } \\
\text { yang positif dan } \\
\text { signifikan terhadap } \\
\text { Organizational } \\
\text { commitment } \\
\end{array}$ & Mendukung \\
\hline $\mathrm{H}_{5}$ & $\begin{array}{l}\text { Job satisfaction } \\
\text { memiliki pengaruh } \\
\text { negatif dan signifikan } \\
\text { terhadap turnover } \\
\text { intention }\end{array}$ & $\begin{array}{l}\text { Sartika } \\
(2014)\end{array}$ & $\begin{array}{l}\text { Job Satisfaction } \\
\text { memiliki pengaruh } \\
\text { yang positif dan tidak } \\
\text { signifikan terhadap } \\
\text { Turnover Intention. }\end{array}$ & $\begin{array}{c}\text { Tidak } \\
\text { Mendukung }\end{array}$ \\
\hline $\mathrm{H}_{6}$ & $\begin{array}{l}\text { Organizational } \\
\text { Commitment memiliki } \\
\text { pengaruh yang negatif } \\
\text { dan signifikan } \\
\text { terhadap turnover } \\
\text { intention }\end{array}$ & $\begin{array}{l}\text { Indraprasti } \\
(2011)\end{array}$ & $\begin{array}{l}\text { Organizational } \\
\text { Commitment memiliki } \\
\text { pengaruh yang negatif } \\
\text { dan tidak signifikan } \\
\text { terhadap turnover } \\
\text { intention. }\end{array}$ & $\begin{array}{c}\text { Tidak } \\
\text { Mendukung }\end{array}$ \\
\hline
\end{tabular}




\section{Sumber : data diolah}

Analisis selanjutnya terhadap turnover intention maka perlu melihat statistik deskriptif pada dimensi transformational leadership style di tabel 7. Pada tabel tersebut bahwa individualized consideration adalah memiliki nilai rata-rata terkecil sebesar 3.7708. Maka tahap selanjutnya menganalisis pada statistik deskriptif pada tabel 4 yang menggambarkan setiap indikatornya dengan melihat rata-rata yang nilainya terkecil.

Tabel 7. Statistik Deskriptif Pada Indikator Individualized Consideration

\begin{tabular}{cccccc}
\hline Indikator & & Minimum & Maximum & Mean & Std. Deviation \\
\hline IC1 & 192 & 1.00 & 5.00 & 3.75 & 0.892 \\
\hline IC2 & 192 & 1.00 & 5.00 & 3.79 & 0,849 \\
\hline
\end{tabular}

Sumber : data diolah

Hasil indikator terendah terletak pada IC1 dengan nilai-rata sebesar 3.75 dan standar deviasi 0.892 sedangkan IC2 nilai rata-rata sebesar 3.79 dan standar deviasi 0.849 , dari hasil diatas perlu diperinci kembali dengan melihat dari segi tingkat pendidikan karyawan diantara dua indikator tersebut pada table 8 .

Tabel 8. Statistik Deskriptif padaTingkat Pendidikan dalam IC1 dan IC2

\begin{tabular}{|c|c|c|c|c|c|c|}
\hline Variable & $\begin{array}{c}\text { Tingkat } \\
\text { Pendidikan }\end{array}$ & & Minimum & Maximum & Mean & $\begin{array}{c}\text { Std. } \\
\text { Deviation }\end{array}$ \\
\hline \multirow[t]{7}{*}{ IC1 } & SD & 46 & 1.00 & 5.00 & 3.63 & 0.974 \\
\hline & SLTP & 38 & 2.00 & 5.00 & 3.82 & 0.896 \\
\hline & SLTA & 82 & 1.00 & 5.00 & 3.80 & 0,808 \\
\hline & D3 & 3 & 2.00 & 4.00 & 3.00 & 1.000 \\
\hline & S1 & 21 & 2.00 & 5.00 & 3.76 & 0.995 \\
\hline & S2 & 2 & 3.00 & 5.00 & 4.00 & 1.414 \\
\hline & Total & 192 & & & & \\
\hline \multirow[t]{7}{*}{ IC2 } & SD & 46 & 1.00 & 5.00 & 3.65 & 0.849 \\
\hline & SLTP & 38 & 1.00 & 5.00 & 3.82 & 0.926 \\
\hline & SLTA & 82 & 1.00 & 5.00 & 3.85 & 0.833 \\
\hline & D3 & 3 & 2.00 & 5.00 & 3.33 & 1.528 \\
\hline & S1 & 21 & 3.00 & 5.00 & 3.76 & 0.625 \\
\hline & S2 & 2 & 5.00 & 5.00 & 5.00 & \\
\hline & Total & 192 & & & & \\
\hline
\end{tabular}

\section{Sumber: data diolah}

Tabel diatas menunjukkan bahwa tingkat pendidikan D3 adalah yang nilai rata-rata yang paling terkecil terletak pada (IC1 dan IC2 sebesar 3.00 dan 3.33). Hal ini menunjukkan bahwa responden pada tingkat pendidikan D3 menjawab netral terhadap individualized consideration. Analisis selanjutnya pada hipotesis ini adalah dengan melihat nilai rata-rata terkecil dari sepuluh indikator job satisfaction pada tabel 9.

Tabel 9 . Statistik Deskriptif pada Indikator Job Satisfaction

\begin{tabular}{cccccc}
\hline Indikator & $\mathrm{N}$ & Minimum & Maximum & Mean & Std. Deviation \\
\hline JS1 & 192 & 1 & 5 & 3.64 & 1.024 \\
\hline JS2 & 192 & 1 & 5 & 3.79 & 0.955 \\
\hline JS3 & 192 & 1 & 5 & 3.53 & 0.915 \\
\hline JS4 & 192 & 1 & 5 & 3.36 & 0.972 \\
\hline JS5 & 192 & 2 & 5 & 3.71 & 0.763 \\
\hline JS6 & 192 & 1 & 5 & 3.69 & 0.840 \\
\hline JS7 & 192 & 1 & 5 & 3.77 & 0.898 \\
\hline
\end{tabular}


JBEMK | Volume 1, Issue 1 (2021) | 76-86

\begin{tabular}{cccccc}
\hline JS8 & 192 & 1 & 5 & 3.80 & 0.872 \\
\hline JS9 & 192 & 1 & 5 & 3.64 & 0.807 \\
\hline JS10 & 192 & 1 & 5 & 3.54 & 0.874 \\
\hline
\end{tabular}

Sumber : data diolah

Dari hasil pada tabel 9 menunjukkan bahwa indikator JS4 memiliki nilai rata-rata terkecil sebesar 3.36 dan standar deviasi sebesar 0.972 dibandingkan dengan indikator-indikator yang lain memiliki rata-rata $\geq 3.5$. Selanjutnya untuk lebih detail lagi yaitu dengan melihat pada tingkat pendidikan terhadap indikator JS 4 pada tabel 10.

Tabel 10. Statistik Deskriptif pada Tingkat Pendidikan dalam JS4

\begin{tabular}{ccccccc}
\hline Variable & Tingkat Pendidikan & & Minimum & Maximum & Mean & $\begin{array}{c}\text { Std. } \\
\text { Deviation }\end{array}$ \\
\hline JS4 & SD & 46 & 1.00 & 5.00 & 3.26 & 1.042 \\
\hline SLTP & 38 & 1.00 & 5.00 & 3.24 & 1.149 \\
\hline SLTA & 82 & 2.00 & 5.00 & 3.54 & 0.905 \\
\hline D3 & 3 & 2.00 & 4.00 & 3.00 & 1.000 \\
\hline S1 & 21 & 2.00 & 4.00 & 3.14 & 0.655 \\
\hline S2 & 2 & 4.00 & 4.00 & 4.00 & \\
\hline Total & 192 & & & & \\
\hline
\end{tabular}

Sumber: data diolah

Dari hasil diatas menunjukkan bahwa nilai rata-rata terkecil sampai terbesar pada tingkat pendidikan D3 sebesar 3.00 dan standar deviasi sebesar 1 diikuti dengan yang lain SD, SLTP dan S1 yang belum mencapai rata-rata 4.00 .

Tabel 11. Statistik Deskriptif pada Indikator Organizational Commitment

\begin{tabular}{cccccc}
\hline Indikator & $\mathrm{N}$ & Minimum & Maximum & Mean & Std. Deviation \\
\hline OC1 & 192 & 1 & 5 & 3.91 & 0.845 \\
\hline OC2 & 192 & 2 & 5 & 3.98 & 0.745 \\
\hline OC3 & 192 & 1 & 5 & 3.74 & 0.956 \\
\hline OC4 & 192 & 2 & 5 & 3.98 & 0.769 \\
\hline OC5 & 192 & 1 & 5 & 3.64 & 0.774 \\
\hline OC6 & 192 & 1 & 5 & 3.81 & 0.925 \\
\hline
\end{tabular}

Sumber : data diolah

Dari hasil pengolahan data pada tabel 11 menunjukkan bahwa semua indikator organizational commitment memiliki nilai rata-rata $\geq 3.5$. Hal ini menunjukkan bahwa semua karyawan yang bekerja di PT. Austindo Nusantara Jaya Agri Tbk di Medan sudah komit terhadap perusahaan. Selanjutnya pada tabel 12 adalah hasil estimasi job satisfaction memediasi pengaruh transformational leadership style terhadap turnover intention dan menguji organizational comitment memediasi pengaruh transformational leadership style terhadap turnover intention dengan menggunakan sobel test. Tabel 14 menunjukkan hasil uji hipotesis indirect effect.

Tabel 12. Hasil Estimasi Indirect Effect Model Sobel Test

\begin{tabular}{clcccc}
\hline Hipotesis & \multicolumn{1}{c}{ Deskripsi } & Estimasi & Nilai Z & 2-Tailed P & Kesimpulan \\
\hline H7 & $\begin{array}{l}\text { Job Satisfaction memediasi } \\
\text { pengaruh Transformation } \\
\text { Leadership Style terhadap } \\
\text { Turnover Intention }\end{array}$ & 0.042 & 0.557 & 0.577 & Ho diterima \\
\hline
\end{tabular}




\begin{tabular}{clllll} 
& $\begin{array}{l}\text { Organizational Comitment } \\
\text { memediasi pengaruh }\end{array}$ \\
Transformational Leadership & -0.0056 & -0.124 & 0.901 & Ho diterima \\
Style terhadap Turnover & & & & \\
Intention & & & \\
\hline Sumber: data diolah
\end{tabular}

Tabel 13. Hasil Uji Hipotesis Indirect Effect

\begin{tabular}{|c|c|c|c|c|}
\hline Hipotesis & Deskripsi & Peneliti & Hasil Test & Keimpulan \\
\hline $\mathrm{H}_{7}$ & $\begin{array}{l}\text { Job Satisfaction dapat } \\
\text { memediasi pengaruh } \\
\text { Transformation } \\
\text { Leadership Style } \\
\text { terhadap Turnover } \\
\text { Intention }\end{array}$ & $\begin{array}{l}\text { Lim et all } \\
\text { (2017) }\end{array}$ & $\begin{array}{l}\text { Job Satisfaction tidak } \\
\text { dapat memediasi } \\
\text { pengaruh } \\
\text { Transformation } \\
\text { Leadership Style } \\
\text { terhadap Turnover } \\
\text { Intention. }\end{array}$ & $\begin{array}{c}\text { Tidak } \\
\text { Mendukung }\end{array}$ \\
\hline $\mathrm{H}_{8}$ & $\begin{array}{l}\text { Organizational } \\
\text { Comitment dapat } \\
\text { memediasi pengaruh } \\
\text { Transformation } \\
\text { Leadership Style } \\
\text { terhadap Turnover } \\
\text { Intention. }\end{array}$ & $\begin{array}{c}\text { Gul et al } \\
\text { (2012) }\end{array}$ & $\begin{array}{l}\text { Organizational } \\
\text { Comitment tidak } \\
\text { dapat memediasi } \\
\text { pengaruh } \\
\text { Transformation } \\
\text { Leadership Style } \\
\text { terhadap Turnover } \\
\text { Intention. }\end{array}$ & $\begin{array}{c}\text { Tidak } \\
\text { Mendukung }\end{array}$ \\
\hline
\end{tabular}

Sumber : data diolah

\section{KESIMPLAN DAN SARAN}

Dengan berdasarkan dari hasil temuan dan pengujian hipoetsis yang telah dijelaskan pada bab sebelumnya, berikut beberapa kesimpulan yang dapat diambil dari hasil penelitian ini: (1) Hasil pengujian transformational leadership style terdapat pengaruh yang positif dan signifikan terhadap job satisfaction; (2) Transformational leadership style memiliki pengaruh yang positif dan signifikan terhadap organizational commitment; (3) Transformational leadership style memiliki pengaruh yang negatif dan signifikan terhadap turnover intention; (4) Job satisfaction terbukti memiliki pengaruh positif dan signifikan terhadap organizational commitment; (5) Job satisfaction memiliki pengaruh positif dan tidak signifikan terhadap turnover intention; (6) Variabel organizational commitment memiliki pengaruh yang negatif dan tidak signifikan terhadap turnover intention; (7) Job satisfaction tidak dapat memediasi pengaruh transformational leadership style terhadap turnover intention; (8) Organizational commitment tidak dapat memediasi pengaruh transformational leadership terhadap turnover intention.

\section{Implikasi Manajerial}

Dengan mengetahui bahwa turnover intention dipengaruhi oleh transformational leadership style secara lansung maupun tidak lansung oleh job satisfaction dan organizational commitment, maka untuk menghilangkan turnover intention pada perusahaan, manajer perlu meningkatkan: (1) Dimensi dari transformational leadership style yaitu individualized consideration terutama pada tingkat pendidikan D3 yang memiliki rata-rata terendah sebesar $3.33 \leq 3.5$ dengan cara: (a) manajer meluangkan waktunya untuk pendidikan dan pengajaran terutama dalam pekerjaan mereka, agar mereka dapat bekerja lebih baik dan efektif; (b) membantu dalam mengembangkan berbagai macam kekuatan (baik fisik maupun intelektual) agar keterampilan para karyawan dan pengetahuan mereka dalam pekerjaan menjadi meningkat. (2) Job satisfaction dengan cara manajer meningkatkan reward karyawan, supaya karyawan akan menjadi senang, giat, semangat, dan lebih rajin dalam bekerja di perusahaan, terutama yang perlu diperhatikan sekali adalah pada jenjang pendidikan yang memiliki rata-rata $\leq 3.5$ yaitu D3 (3.00), S1 (3.14), SLTP (3.24) dan SD (3.26). 


\section{Saran Untuk Penelitian Selanjutnya}

Penelitian ini memiliki keterbatasan masalah yang mencakup tujuan penelitian yaitu untuk menganalisis pengaruh dari transformational leadership style, job satisfaction terhadap turnover intention dengan organizational commitment sebagai mediating variable. Berkaitan dengan hasil temuan ini, maka saran-saran yang dianjurkan untuk penelitian selanjutnya antara lain: (1) Melakukan penelitian lanjutan dengan menambahkan variable transactional leadership style selain transformational leadership style untuk melihat perilaku manajer yang memfokuskan perhatiannya pada transaksi interpersonal antara manajer dengan bawahannya yang melibatkan hubungan kesepakatan mengenai klarifikasi sasaran, standar kerja, penugasan kerja, dan penghargaan terhadap bawahannya. Hal ini diambil berdasarkan penelitian oleh Gul at al (2012) dengan judul leadership styles, turnover intention and the mediating role of organizational commitment. Information and Knowlage Managemen. Information and Knowledge Management; (2) Melakukan penelitian terhadap indikasi turnover intention dengan memasukkan variabel lain seperti stress kerja, konflik antar karyawan dan budaya organisasi. Hal ini diambil berdasarkan saran dari penelitian dari Sartika (2014) dengan judul Pengaruh job satisfaction dan transformational leadership style terhadap turnover intention dengan organizational commitment sebagai mediating variable, Studi Kasus di CV. Putra Tama Jaya.

\section{REFERENCES}

Bramantara, B., dan Dewi, K. (2015). Pengaruh Kepuasan Kerja dan Komitmen Organisasi Terhadap Turnover Intention Karyawan Pada Krisna Oleh - Oleh Khas Bali III. Jurnal Ilmu Manajemen, 4(1): 1-20.

Gul S, Ahmad B, Rehmahn S.U, Shabir N, Razzaq, N. (2012). Leadership styles, turnover intention and the mediating role of organizational commitment. Information and Knowlage Managemen. Information and Knowledge Management, ISSN 2224-5758 (Paper) ISSN 2224-896X (Online), Vol. 2, No. 7, Hal. 44-51.

Hair, J. F., Black, W. C., Babin, B. J., \& Anderson, R. E. (2010). Multivariate Data Analysis. New York: Pearson.

Hasan, Lenny. (2012). Pengaruh Kepuasan Kerja dan Disiplin Kerja Terhadap Komitmen Organisasi Pegawai Dinas Perindustrian Perdangan Pertambangan dan Energi Kota Padang. Jurnal Manajemen dan Kewirausahaan, 3 (1), h: 57-92.

Indraprasti, Devinthia. (2011). Pengaruh Komitmen Organisasional, Kepuasan Kerja, dan Stres Kerja Terhadap Intensi Keluar Studi Pada Karyawan Alih Daya (Outsourcing) PT. Bank Rakyat Indonesia di Wilayah Yogyakarta. Tesis Megister Manajemen: Universitas Gadjah Mada.

Indriyani, Etty., dan Haryono Wisnu P.C. (2011). Pengaruh Budaya Organisasi dan Kepuasan Kerja terhadap Kinerja Karyawan dengan Komitmen Organisasional sebagai Variable Intervening pada Workshop SMK Katolik Santo Mikael. Jurnal STIE AUB. 1(1): 21-45.

Ismail, A., Mohamed, H. A.-B., Sulaiman, A. Z., Mohamad, M. H., \& Yusuf, M. H. (2011). An Empirical Study of the Relationship Between Transformational Leadership, Empowerment and Organizational Commitment. Business and Economics Research Journal, 2 (1), 89-107.

Kumar, R., Charles, R., and Peter Y. (2011). A Study on Turnover Intention in Fast Food Industry: Employees' Fit to the Organizational Culture and the Important of their Commitment. International Journal of Academic Research in Business and Social Sciences, 2 (5), pp: 9-42. 
Lekatompessy, J.E. (2003). Hubungan Profesionalisme dengan konsekuensinya: Komitmen Organisasional, Kepuasan Kerja, Prestasi Kerja dan Keinginan Berpindah (Studi Empiris di Lingkungan Akuntan Publik). Jurnal Bisnis dan Akuntansi, 5(1): 69-84.

Lim, A.J.P., Loo, J.T.K \& Lee, P.H. (2017). The Impact of Leadership on Turn Over Intention: The Mediating Role of Organization Commitment and Job Satisfaction. Journal of Applied Structural Equation Modeling, 1(1), 27-41.

Mangkunegara, A.P. (2009). Manajemen Sumber Daya Manusia Perusahaan. Bandung: PT.Remaja Rosdakarya.

Mathis, R.L dan Jackson, J.H. (2016). Human Resource Management. USA: Cengage Learning.

Nagar, K. (2012). Organizational Commitment and Job Satisfaction among Teachers during Times of Burnout. Vikalpa: The Journal for Decision Markets, 37(2): 1-18.

Ngadiman, A. E., and Ratmawati, D. (2013). Influence of Transformational Leadership and Organization Climate to the Work Satisfaction, Organizational Commitment and Organizational Citizenship Behavior on the Educational Personnel of Sebelas Maret University Surakarta. European Journal of Business and Management, 5(10): 97-114

Panggabean, Mutiara S. (2004). Manajemen Sumber Daya Manusia. Bogor: Ghalia Indonesia.

Robbins, Stephen P., and Timothy A. Judge. (2015). Organizational Behaviour. Pearson educational Limited: England.

Sartika, Dwi. (2014). Pengaruh Kepuasan Kerja dan Gaya Kepemimpinan Transformasional terhadap Keinginan Keluar Karyawan dengan Komitmen Organisasi sebagai Variabel Mediasi (Studi Kasus di CV. Putra Tama Jaya). Management Analysis Journal, Vol.3, No.2.

Sekaran, U., \& Bougie, R. (2013). Research methods for business.. New York: John Wiley \& Sons, In.

Sugiyono (2009). Metode Penelitian Kuantitatif Kualitatif dan R\&D. Alfabeta, CV: Bandung.

Tejada, J. J., Raymond, J., \& Punzalan, B. (2012). On the Misuse of Slovin's Formula. The Philippine Statistician, 61(1), 8 .

Zahari, I., and Shurbagi, A. (2012). The Effect of Organizational Culture and the Relationship between Transformational Leadership and Job Satisfaction in Petroleum Sector of Libya. International Business Research, Vol 5, No 9, pp.89-975 